Grzegorz MENTEL, PhD, DSc (Corresponding author)

Department of Quantitative Methods

University of Information Technology and Management in Rzeszow

E-mail: gmentel@wsiz.edu.pl

Yuriy BILAN, PhD, DSc

Tomas Bata University in Zlin, Zlin, Czech Republic

Sumy State University, Sumy, Ukraine

E-mail: y.bilan@prz.edu.pl

Beata SZETELA, PhD

Department of Quantitative Methods

Rzeszow University of Technology, Rzeszow, Poland

E-mail: beata@prz.edu.pl

Urszula MENTEL, MBA

Department of Projects Management and Security Policy

Rzeszow University of Technology, Rzeszow, Poland

E-mail: u.mentel@prz.edu.pl

\title{
WEATHER DERIVATIVE INSTRUMENTS. PROPERTY ANALYSIS OF THE BASIC INSTRUMENTS
}

\begin{abstract}
The issues of weather risk management, and more specifically the problem of protecting against it in terms of the so-called weather financial instruments are the subject of this paper. The article is devoted to the characteristics of the temperature weather factor as a base instrument in terms of meteorological forecasts. It refers to the methodology of weather forecasts in the light of their usefulness, statistical analysis of the properties of the selected weather factor and the nature of the variability of weather indexes.
\end{abstract}

Keywords: weather, derivative instruments, risk.

JEL Classifications: C100, C500, G100, G320

\section{Introduction}

Weather derivatives are financial instruments whose value depends on meteorological values. The basics factor is the basic meteorological event, which is considered as non-catastrophic. Their application is based on standard economic risk management practices such as currency risk and interest rates. However, the basics instruments of the weather futures contracts differ significantly from others commonly used in derivative instruments. They relate to atmospheric phenomena, 
i.e. non-economic but countable values. In their case, it is not possible to buy or sell the weather factor. Weather cannot be stored either. The embedded basic instrument in the case of weather contracts are weather conditions, whose data are collected from specific meteorological stations (Kupczyk, 2003).

Referring both to their structure and the concept of effective weather management, it is important to consider weather factors in the context of meteorological forecasts. This is important as any attempts to detail the weather risk management have a positive effect on the improvement of the system as a whole. Hence, it seems necessary to get to know the structure of the subject of the study, both from the point of view of historical behavior, distributions, and possible prognostic possibilities. All activities in this area are aimed at reducing the uncertainty related to the occurrence of non-extreme weather events. This, in turn, translates into increased efficiency of risk management both in terms of weather time series analyzes (Bilan et al., 2020; Tarczyński et al., 2021) and the analyzes of the distribution of basic instruments, which are a kind of "input" into more complex financial instruments, such as the aforementioned weather instruments derivatives. Regardless of the approach to the problem and the context of its approach, in each variant there is an economic aspect around which the risk mitigation process revolves. Each inaccurate forecast translates into negative results of economic entities or state institutions.

\section{The use of derivatives in managing the risk of non-catastrophic weather events}

In order to describe a weather derivative, an attempt should be made to define it first. Further considerations will then be more readable and consistent. When formulating this type of definition, one should refer to the general definition of derivative instruments, according to which they are financial instruments with a value that depends on the value of the basic instrument (Hull J., 2009). Thus, in relation to derivative weather instruments, the role of the aforementioned parameter is played by weather factors specific in a given case. Those, in turn, calculated on the basis of weather indices have a numerical dimension, which is necessary for the valuation and settlement of concluded contracts. Therefore, it is a contract between two parties. It determines the terms of payment between those who settle a given transaction, depending on the occurrence of specific weather events during its duration. Referring to the essence of derivatives, also in the case of forward weather transactions, each contract with their participation should be characterized by precisely defined parameters (Jewson and Brix, 2005):

- specified contract period - the date of its conclusion and completion,

- indicated primary and backup measurement station - data source,

- basic weather index being the basis for the settlement of the contract, referring in its structure to one or more weather variables,

- specific payment function - a specific method of calculating payments for both parties to the contract in relation to the value of the basic index. 
In addition, it is also important to specify the type of contract itself (forward/ future, option, swap). Weather-based contracts are only a component of modern derivatives. Within this group, two types of forward transactions can be distinguished, which by their nature refer to the risk of weather events.

One of them are catastrophe derivatives, also known as catastrophic ones. Regardless of the name, they are used to protect against catastrophic risks. As it can be concluded, the weather risk of this type, underlying the aforementioned term contracts, relates to events of significant damage. As already mentioned, such incidents are also the product of natural forces, but the scale of their impact is really large and the frequency of their occurrence is relatively rare. The second of the groups refers to the previous considerations, i.e. to the events of a noncatastrophic nature, these are typical weather derivatives. The risk and the scale they relate to are much less intense. Obviously, like each of the considered ones, these also serve to protect against unfavorable weather conditions. When dividing within the weather futures contracts alone (Figure 1), five categories should be distinguished.

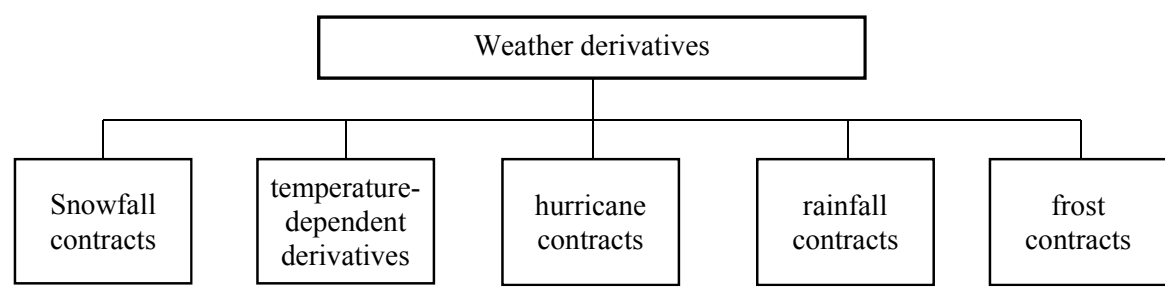

Figure 1. Types of weather derivatives Source: The authors' own research

However, there should be many more types of weather derivatives, because the type of the basic index determines the type of the contract, and the scope is much wider. In addition to temperature, wind speed or all kinds of precipitation, the basic indexes are also humidity indexes or combinations of the abovementioned (Banks, 2002; Majewska, 2013; L'opez Cabrera and Hardle, 2007; Hull J., 2009; Campbell and Diebold, 2005 ).

The basic indices of weather derivatives listed in table 1 include also other over-the-counter (OTC) derivatives. In this market transactions are very often tailored to the individual needs of the parties to the contract, hence one also deals with an individual approach to the contracts themselves (Corbally and Dang, 2002; Schulzweid and Quast, 2005). There are, for instance, REDs (Rain Event Days) index, which defines the number of rainy days, SEDs (Snow Event Days), which defines the number of days with snowfall. There are also indices constructed for the needs of given industries. Here one can specify ACDs (Adverse Construction Days) responsible for the number of unfavorable days in construction, its 
counterpart in trade ARDs (Adverse Retail Days), or basic values created for the needs of agriculture, such as GDD (Growing Degree Day) relating to the limit temperature, necessary for proper plant growth, the MGDD index (Modified Growing Degree Day) which takes into account both the lower and upper temperature threshold appropriate for a given type of plant.

Table 1. List of basic instruments for weather derivatives

\begin{tabular}{|c|c|c|}
\hline $\begin{array}{c}\text { Weather } \\
\text { derivatives }\end{array}$ & Weather index & Index characteristics \\
\hline \multirow{7}{*}{ Temperature } & HDD (Heating Degree Day) & Heating Degree Day \\
\hline & CDD (Cooling Degree Day) & Cooling Degree Day \\
\hline & EDD (Energy Degree Day) & Sum of HDD and CDD indices \\
\hline & $\begin{array}{l}\text { CAT (Cumulative Average } \\
\text { Temperature) }\end{array}$ & Cumulative Average Temperature \\
\hline & $\begin{array}{l}\text { CTD (Critical Temperature } \\
\text { Day) }\end{array}$ & $\begin{array}{l}\text { Number of days with a temperature } \\
\text { below the critical temperature }\end{array}$ \\
\hline & CDH (Chilling Degree Hour) & $\begin{array}{l}\text { Number of hours with a } \\
\text { temperature below the threshold }\end{array}$ \\
\hline & GDD (Growing Degree Day) & $\begin{array}{l}\text { Number of days with temperature } \\
\text { above the basic one }\end{array}$ \\
\hline \multirow{4}{*}{ Falls } & CRD (Critical Rainfall Day) & $\begin{array}{l}\text { Number of days with critical } \\
\text { rainfall }\end{array}$ \\
\hline & CSD (Critical Snowfall Day) & $\begin{array}{l}\text { Number of days with critical } \\
\text { snowfall }\end{array}$ \\
\hline & RFI (Rainfall Index) & Rainfall in $\mathrm{mm}^{3}$ \\
\hline & SFI (Snowfall Index) & Snowfall in $\mathrm{cm} / \mathrm{m}^{2}$ \\
\hline Wind & WSI (Wind Speed Index) & Wind speed in $\mathrm{m} / \mathrm{s}$ \\
\hline Hurricane & CHI (CME Hurricane Index) & $\begin{array}{l}\text { Damage amount in relation to the } \\
\text { maximum wind speed and coverage } \\
\text { area }\end{array}$ \\
\hline
\end{tabular}

One should also remember that, apart from the presented, sophisticated indices, the weather parameter itself may be the basic instrument, obviously resulting from the data of the selected weather station. Often, the average monthly weather parameters in a given location are taken as input.

\section{Weather forecasts - concepts of their use}

Weather forecasts are quite important as they provide information on the future behavior of weather conditions. In addition, they are one of the factors taken into account in the process of valuation of derivatives, apart from modeling the index distribution or modeling the basic asset. In the context of weather term 
contracts, they are used in the market by both brokers and their clients (Jewson, 2002).

Brokers use weather forecasts before concluding a contract in order to make any adjustments to the price of the instrument. During the term of the contract, forecasts are used primarily to manage the portfolio containing such instruments. Therefore, all forecasts of the weather factors behavior for the needs of the market are constructed both before the date of the term contract and during its duration.

On the other hand, clients represented by economic operators usually use forecasts to make decisions. The question is whether, during a period of importance to them, there may be unpredictable weather events that may ultimately turn out to be extremely unfavorable. If so, a given entity usually decides on the form of controlling this risk, which indirectly translates into effective management of it. For instance, a company may choose financial derivative instruments as a way, a form of possible risk transfer. Taking a possible decision to transfer the risk with the use of the indicated derivative weather instruments causes that the analyzed group of clients often wants to anticipate possible financial flows. Well-managed companies, during the term of such futures contracts, track the values of the index which a given instrument is based on, adjusting the number of contracts they hold accordingly. Its purpose is to recover part of the funds allocated by them as collateral. It is about a situation where exceptionally favorable weather conditions occur during the term of the contract for a given company.

Moving on to the discussed problem of weather forecasts, a preliminary attempt should be made to define the problem. This type of forecast is formally interpreted as an indication of the future, most probable weather condition. This, of course, applies to a given place or area on the basis of knowledge of its present state, as well as the laws governing atmospheric processes.

Table 2. Division of weather forecasts

\begin{tabular}{|l|c|}
\hline \multicolumn{1}{|c|}{ Forecast category } & The horizon of forecast \\
\hline current & shorter than 2 hours \\
\hline one-day & $12-24$ hours \\
\hline short-term & $12-72$ hours \\
\hline medium-term & $3-12$ days \\
\hline seasonal & $1-3$ months \\
\hline climate long-term & 6 months / 1-2 years \\
\hline multi-year climate forecast & 2 and more years \\
\hline
\end{tabular}

Source: The authors' own research based on Banks, E., (2002), Weather Fundamentals, [in]: Banks, E. (ed.), Weather Risk Management, Palgrave, pp. 42

Regardless of the level of specification (Table 2), individual types of forecasts are made on the basis of the same information and, to a certain extent, refer to similar periods. Thus, apart from the issue of the forecast horizon, it can be mentioned that the current forecasts predict extreme weather events, such as 
hurricanes or tornadoes. On the other hand, one-day forecasts refer more to severe storms and other annoying weather anomalies. The most common type of weather forecast is the short-term forecast. It is most often reported in the media, hence its greatest popularity. It refers to such meteorological factors as the air temperature during the day, in terms of minimum and maximum, atmospheric pressure, the amount of precipitation, the movement of warm and cold air masses, or finally the speed and direction of the wind. A forecast of this type for an average recipient is often enriched with elements such as black ice fog or frost. Medium-term forecasts, which are another category, are somewhat less informative as they contain information that is limited more to air pressure, the amount of possible precipitation and average values of air temperature during the day. The next type of seasonal prediction is the least detailed. Under such conditions, information is obtained about the average values of air pressure, precipitation and air temperature. Hence, it is viewed as of little use, mainly because it contains relatively little data (Ziehman, Brix i Jewson, 2002). The remaining categories, i.e. long-term and multi-year forecasts, are based on information on deviations from long-term average air temperature values or, as in the case of the latter, mentioned in the estimation of multi-year temperature trends on an annual basis.

Another division of weather forecasts is their differentiation due to the method applied for their determination. The numerical method in the forecast of atmospheric conditions is basically based on statistical methods or on the basic principles of physics, and the predictions obtained as a result of its application are obtained by solving a specific system of equations. The synoptic method, in turn, refers to the analysis of real conditions and the critical analysis of numerical forecasts.

Formally, other classifications of weather forecasts could be made, for example in terms of the area they are to relate to, but this is not the main purpose of this paper. The issues of weather data and forecast sources are more important as the estimation results from the forecasting models differ, even though they formally use the same data. However, it is impossible to clearly describe the processes taking place in the atmosphere, thus enabling reliable forecasting of their course. There are many reasons for this, including the quality and quantity of data. Moreover, the issue of their assimilation is important. Other problems that one has to deal with are the numerical solution of the equations used to estimate the predictions and the so-called parameterization. Therefore, the process is more complex than might be expected.

When referring to the weather data, a clear division in this respect should be emphasized. All measurements of weather parameters take place directly or indirectly.

In addition to the issue of data sources, there is also their assimilation. There are many sources of data, and in addition they are collected in different places on earth and at different times. However, this raises some compatibility problems. The aforementioned assimilation is a complex process that is divided into two stages: the first relates to data quality checking aimed at eliminating obvious measurement 
errors, the second is data reconciliation, and the use of information available earlier, namely from previous hours or days.

Forecasts and their sources are also important issues. However, a clear distinction should be made between forecasts with shorter and longer forecast horizons.

In the first variant, i.e. forecasts not exceeding 10 days, one should distinguish: immediate forecasts (up to 2 hours), ultra-short-term forecasts (from 2 to 12 hours), short-term forecasts (from 12 to 72 hours), medium-term forecasts (from 72 to 240 hours). In order to make this division, each country has an agency, a government institution. This institution is also responsible for the process of collecting weather data.

Without going into the issue of specific forecasting models, it should be emphasized that they are designated for small areas (Melonek, 2011).

On the other hand, in the case of seasonal or long-term forecasts, more general estimates are obtained, based on the average values of a given indicator, as previously described. In this case, they relate to large areas of the country, and even continents, but they are designated by two institutions around the world, i.e. the European Center for Medium Range Weather Forecasts (ECMRWF) (Unisys Weather Information Systems, 2016) and National Weather Service (NWS) (National Oceanic \& Atmospheric Administration, U.S. Department of Commerce, 2016).

As for the use of the discussed forecasts in the weather derivatives market, short- and medium-term forecasts are important. This is mainly for purely practical reasons.

The issues of including forecasts in the so-called the valuations are not the same in terms of the types of forecasts discussed. Moreover, their actual use in this process is relatively rare, as most transactions on this type of market are concluded well before the date of execution of such a contract (Mentel, 2017). Then there are no forecasts for this period yet.

Accuracy of the forecasts themselves is another point of contention. As indicated, for example, by S. Jewson (Jewson, 2001), only short- and medium-term meteorological predictions are useful as the resulting errors are smaller than those obtained by other methods. J. Shorter comments in a similar vein, detailing the Jewson's statement. It states that all forecasts with a horizon longer than 10-12 days are subject to such a large error that their usefulness in the process of valuation of weather derivatives loses its value (Shorter, Crawford i Boucher, 2002). This error often reaches the level of around five degrees Celsius, which, given such a short period of time, makes such forecasts of little use in the context of the valuation of contracts with longer delivery times.

In the case of seasonal or long-term forecasts, the issue is even worse. Possible deviations from the actual weather conditions are even greater than those previously discussed. An example of this type of discrepancy is given in P. Forrest in his publication (Forrest, 2002). Considering that these forecasts often cover 
several months, the possible costs of business entities resulting from their lack of accuracy may be extremely high. An example may be the situation when the heating season has been an exceptionally warm period for many years, and all predictions announced a lower temperature than the so-called historical average. Then, all the consequences can be catastrophic, and such a large inconsistency in the prediction confirms that the valuation of weather futures contracts based on meteorological forecasts may be heavily burdened.

\section{Property analysis of the basic instruments}

In order to later verify the market forecasting models using the example of weather instruments, an analysis of the basic instruments should be presented. In this case they are created by the above-mentioned meteorological factors. Making a description of the "input element" can prove extremely helpful in any attempts to predict weather data. These factors do not necessarily need to have analogous properties that can be observed, for example, when analyzing financial instruments.

Firstly, in case of the weather data, there may be strong asymmetries in the distribution, and secondly, the phenomenon of seasonality can be observed. All such observations, if they are confirmed by empirical research, may constitute the basis for the correct selection of forecast methods and drawing the right conclusions when applying them.

Therefore, the following analysis is intended to contribute to the possible disclosure of certain unique features, foreign to financial instruments, which in turn - as it has been presented - should be taken into account in the modeling process (Endress, 2018; Oliinyk, 2019). The subject of the analyzes is an attempt to answer the question whether the values of the weather factors under study are characterized by a certain tendency over time, whether they are characterized by the phenomenon of autocorrelation, or whether factors of this type are characterized by seasonality. It is also important whether the variance of a given weather factor is homogeneous and constant over time. By answering these questions, one can additionally obtain information about the distributions of the values of a given weather factor.

The authors limit the review of weather factors to the temperature. Information on this instrument is the most desirable among potential interested parties, and if we take into account the market of weather derivatives, the temperature is the basic element in the context of indexing.

Thus, initially making a general characterization on the basis of annual data, a significant upward trend can be observed, which is in a way explained by the effect of the increasing so-called global warming (Figure 2). Similar conclusions can also be observed on the analogous data on individual weather stations in our country. The observed trend is therefore "generally prevailing".

An interesting phenomenon is a similar data analysis for monthly periods. Their seasonality is clearly visible here, which could be expected. Although a graphic presentation (Figure 2) refers only to the average monthly temperature in 
Weather Derivatives Instruments. Property Analysis of the Basic Instruments

the Subcarpathian Province, i.e., it is closely correlated with analogous indications across other provinces or individual cities.
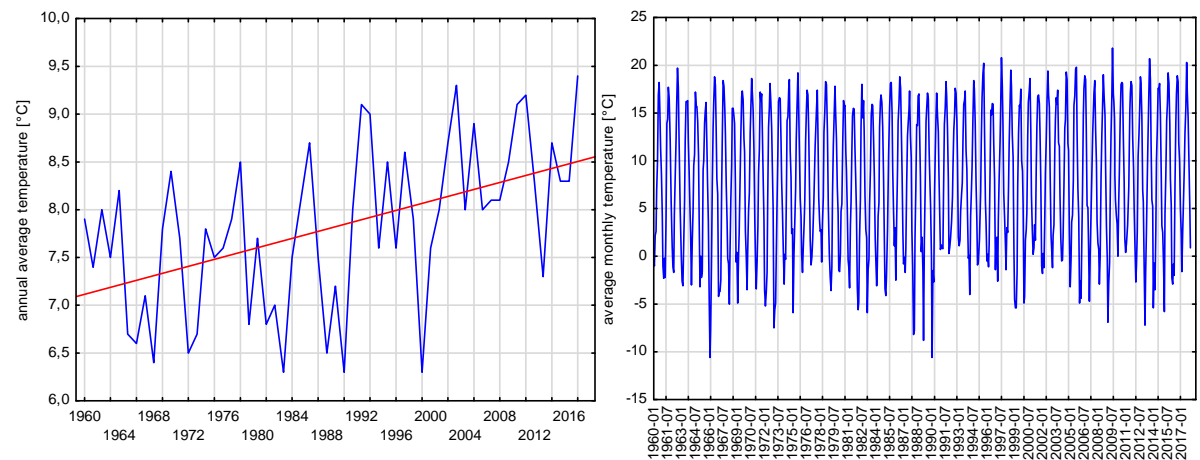

Figure 2. Formation of the average annual and monthly air temperature in the Subcarpathian Province in 1960-2017

Source: The authors' own research

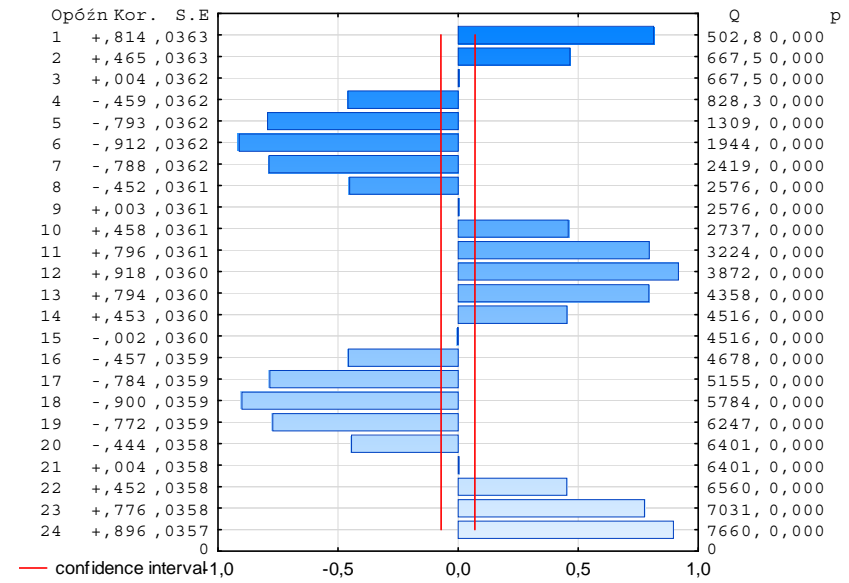

Figure 3. Autocorrelation function for the average monthly air temperature in the Subcarpathian Province in 1960-2017

Source: The authors' own research

It also seems reasonable to check whether we deal with the effect of data autocorrelation. With such significant seasonality, the scale of the considered phenomenon should be significant, which confirms Figure 3.

When analyzing the issue of seasonality (Figure 4) and the autocorrelation for daily data, it should be confirmed that also in this case one deals with both of these phenomena. However, the nature of the autocorrelation changes somewhat. The 
Grzegorz Mentel, Yuriy Bilan, Beata Szetela, Urszula Mentel

statistics of the Ljung-Box test confirm the occurrence of the correlation phenomenon over time, but it fades exponentially.

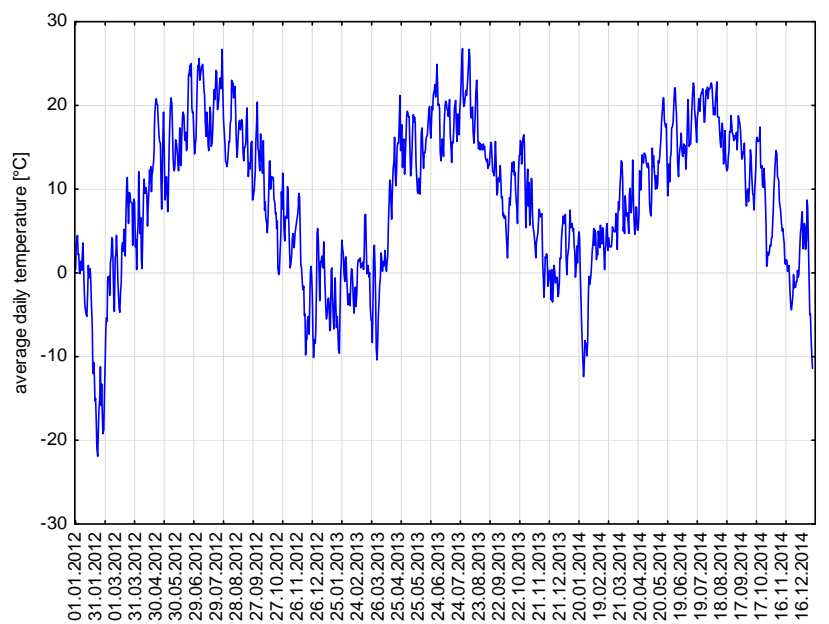

Figure 4. Examples of daily temperature values for the Subcarpathian Province in 2012-2014

Source: The authors' own research

Table 3. Exemplary results of selected parameters of temperature distribution $\left[{ }^{\circ} \mathrm{C}\right]$

\begin{tabular}{|c|c|c|c|c|c|c|c|}
\hline & 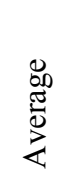 & 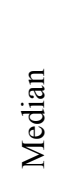 & $\begin{array}{l}\bar{\pi} \\
\bar{Z}\end{array}$ & $\underset{\Xi}{\stackrel{\Xi}{\Xi}}$ & 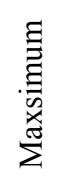 & 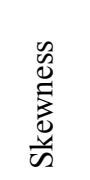 & $\begin{array}{l}\frac{n}{5} \\
0 \\
\stackrel{\Xi}{\Xi} \\
\underline{\Xi}\end{array}$ \\
\hline & \multicolumn{7}{|c|}{ for Poland } \\
\hline Annual data ${ }^{1}$ & 7.74 & 7.85 & 8.00 & 5.80 & 9.40 & -0.14 & -0.65 \\
\hline Monthly data & 7.74 & 7.95 & size & -11.2 & 21.8 & -0.14 & -1.13 \\
\hline \multirow[t]{2}{*}{ Daily data ${ }^{2}$} & 8.70 & 9.14 & size & -17.4 & 25.7 & -0.35 & -0.41 \\
\hline & \multicolumn{7}{|c|}{ for Rzeszów } \\
\hline Annual data & 8.09 & 8.07 & 8.41 & 5.97 & 11.1 & 0.30 & 0.36 \\
\hline Monthly data & 8.08 & 8.20 & 16.8 & -13.1 & 22.3 & -0.21 & -1.08 \\
\hline Daily data & 9.48 & 10.1 & 0.70 & -22.3 & 27.6 & -0.31 & -0.30 \\
\hline
\end{tabular}

Source: The authors' own research

\footnotetext{
${ }^{1}$ Descriptive statistics for annual and monthly data were calculated on the basis of the average annual and monthly temperature in Poland and Rzeszów in 1951-2017, respectively.

${ }^{2}$ In turn, the distribution parameters for daily data for Poland and Rzeszów were estimated on the basis of this type of data from 2012-2017.
} 
Weather Derivatives Instruments. Property Analysis of the Basic Instruments

Apart from the graphic presentation, this fact is confirmed by the results of the Ljung-Box $(\mathrm{Q})$ test. With regard to the previously observed seasonality, the relationships between individual months are also clear.

The distribution of the temperature characteristic is also quite interesting. This can be proved by the values of the designated descriptive statistics (Table 3).

Table 4. Results of selected parameters of temperature distribution for Rzeszów in the cross-section of individual months $\left[{ }^{\circ} \mathrm{C}\right]$

\begin{tabular}{|c|c|c|c|c|c|c|c|c|}
\hline & 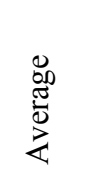 & $\frac{\text { J]త్ }}{\sum_{\Sigma}^{D}}$ & $\begin{array}{l}\bar{\pi} \\
\sum_{0}^{\circ}\end{array}$ & 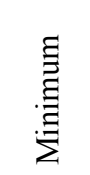 & 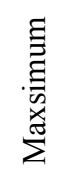 & 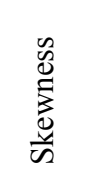 & $\begin{array}{l}\frac{n}{n} \\
\stackrel{0}{\mathscr{V}} \\
\stackrel{\Xi}{\Xi}\end{array}$ & $\begin{array}{l}\mathscr{E} \\
\stackrel{\Xi}{\Xi} \\
\stackrel{\Xi}{*}\end{array}$ \\
\hline & \multicolumn{8}{|c|}{ for monthly data ${ }^{3}$} \\
\hline January & -2.85 & -2.50 & -1.70 & -12.4 & 3.00 & -0.70 & 0.61 & 28.27 \\
\hline February & -1.67 & -1.30 & -0.60 & -13.1 & 4.40 & -0.76 & 0.55 & 43.35 \\
\hline March & 2.40 & 3.00 & 3.10 & -4.60 & 6.80 & -0.66 & -0.23 & 23.88 \\
\hline April & 8.26 & 8.20 & 8.10 & 4.60 & 11.7 & -0.29 & -0.22 & 25.37 \\
\hline May & 13.5 & 13.6 & 13.1 & 9.60 & 16.8 & -0.09 & -0.23 & 12.66 \\
\hline June & 16.7 & 16.6 & 17.0 & 14.3 & 19.2 & -0.03 & -0.72 & 11.05 \\
\hline July & 18.5 & 18.4 & 17.1 & 15.4 & 21.3 & 0.05 & -0.95 & 10.39 \\
\hline August & 17.8 & 17.1 & 17.8 & 14.6 & 22.3 & 0.73 & 1.92 & 14.72 \\
\hline September & 13.4 & 13.1 & 12.8 & 10.3 & 16.3 & 0.10 & -0.67 & 13.74 \\
\hline October & 8.53 & 8.30 & 8.20 & 5.70 & 12.5 & 0.43 & -0.26 & 20.68 \\
\hline November & 3.56 & 4.00 & 5.90 & -2.70 & 7.40 & -0.61 & 0.29 & 18.76 \\
\hline \multirow[t]{2}{*}{ December } & 8.08 & -0.45 & -0.40 & -6.80 & 3.40 & -0.48 & -0.39 & 20.60 \\
\hline & \multicolumn{8}{|c|}{ for daily data ${ }^{4}$} \\
\hline January & -1.18 & 0.35 & 0.90 & -15.2 & 9.20 & -0.75 & -0.10 & 10.18 \\
\hline February & -1.39 & 0.50 & 2.00 & -22.3 & 7.90 & -1.38 & 1.42 & 13.84 \\
\hline March & 3.72 & 4.15 & 5.30 & -10.8 & 14.3 & -0.42 & 0.34 & 6.96 \\
\hline April & 9.52 & 9.95 & 0.70 & 0.10 & 21.2 & -0.01 & -0.60 & 2.56 \\
\hline May & 14.3 & 13.8 & 10.1 & 7.50 & 21.4 & 0.20 & -0.96 & 2.36 \\
\hline June & 17.8 & 17.3 & 15.8 & 11.4 & 25.5 & 0.41 & -0.52 & 1.48 \\
\hline July & 20.4 & 20.4 & 20.9 & 13.2 & 27.4 & 0.03 & -0.73 & 2.14 \\
\hline August & 19.8 & 19.7 & 23.2 & 12.5 & 27.6 & 0.11 & -0.98 & 1.76 \\
\hline September & 14.4 & 14.3 & 14.0 & 6.80 & 27.6 & 0.56 & 1.06 & 2.00 \\
\hline Ocober & 9.20 & 9.45 & 8.80 & -1.10 & 17.6 & -0.14 & -0.68 & 2.25 \\
\hline November & 5.66 & 6.15 & 7.60 & -4.20 & 15.9 & -0.06 & -0.48 & 4.94 \\
\hline December & 0.84 & 1.30 & 1.40 & -10.2 & 10.0 & -0.54 & -0.23 & 5.81 \\
\hline
\end{tabular}

Source: The authors' own research

\footnotetext{
${ }^{3}$ In this case, monthly data from 1951-2017 were used.

${ }^{4}$ The values of statistics in this variant were estimated on the basis of daily data from 2012-2017.
} 
Grzegorz Mentel, Yuriy Bilan, Beata Szetela, Urszula Mentel

It seems justified to conduct a similar analysis across individual months (Table 4). This can lead to quite interesting observations. One of them is that the asymmetry is different in particular seasons: it shifts to the left in winter and to the right in summer. Perhaps sometimes this tendency is not very clear, but this observation is consistent with what J. Preś presented in his work (Preś, 2007).

Apart from the analysis of descriptive statistics, attention should be paid to the nature of the trait distributions themselves.

Table 5. Tests of normality of temperature distributions for Rzeszów in the case of individual months

\begin{tabular}{|c|c|c|c|c|c|c|c|c|}
\hline & 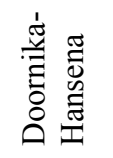 & \begin{tabular}{l}
$\stackrel{0}{\Xi}$ \\
\multirow{2}{*}{} \\
1 \\
0
\end{tabular} & 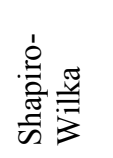 & 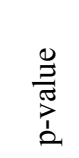 & 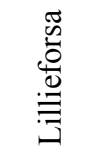 & $\begin{array}{l}\frac{0}{J} \\
\frac{\pi}{2} \\
1 \\
0\end{array}$ & 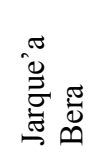 & 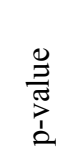 \\
\hline & \multicolumn{8}{|c|}{ for monthly data } \\
\hline January & 3.3615 & 0.19 & 0.9777 & 0.29 & 0.0934 & 0.17 & 3.5172 & 0.17 \\
\hline February & 5.5908 & 0.06 & 0.9647 & 0.06 & 0.0842 & 0.29 & 4.6757 & 0.10 \\
\hline March & 8.8499 & 0.01 & 0.9540 & 0.02 & 0.1124 & 0.04 & 4.4325 & 0.11 \\
\hline April & 0.8584 & 0.65 & 0.9836 & 0.55 & 0.0765 & 0.44 & 0.9423 & 0.62 \\
\hline May & 0.0778 & 0.96 & 0.9941 & 0.99 & 0.0512 & 1.00 & 0.4345 & 0.80 \\
\hline June & 0.4841 & 0.78 & 0.9855 & 0.65 & 0.0722 & 0.54 & 0.8661 & 0.65 \\
\hline July & 3.0770 & 0.25 & 0.9726 & 0.16 & 0.0915 & 0.19 & 2.5509 & 0.28 \\
\hline August & 7.0034 & 0.03 & 0.9660 & 0.07 & 0.1119 & 0.04 & 9.6531 & 0.01 \\
\hline September & 0.9279 & 0.63 & 0.9781 & 0.30 & 0.1003 & 0.1 & 1.3034 & 0.52 \\
\hline October & 3.5062 & 0.17 & 0.9618 & 0.04 & 0.1172 & 0.03 & 2.4937 & 0.29 \\
\hline November & 4.1476 & 0.13 & 0.9684 & 0.10 & 0.0873 & 0.26 & 3.4228 & 0.18 \\
\hline \multirow[t]{2}{*}{ December } & 4.6555 & 0.10 & 0.9684 & 0.10 & 0.1001 & 0.11 & 2.9373 & 0.23 \\
\hline & \multicolumn{8}{|c|}{ for daily data } \\
\hline January & 24.009 & 0.00 & 0.9429 & 0.00 & 0.1430 & 0.00 & 11.432 & 0.00 \\
\hline February & 73.190 & 0.00 & 0.8600 & 0.00 & 0.1562 & 0.00 & 42.967 & 0.00 \\
\hline March & 3.7606 & 0.15 & 0.9843 & 0.16 & 0.0635 & 0.25 & 4.0195 & 0.13 \\
\hline April & 1.6478 & 0.44 & 0.9801 & 0.07 & 0.0591 & 0.37 & 1.9715 & 0.37 \\
\hline May & 9.1700 & 0.01 & 0.9670 & 0.00 & 0.0838 & 0.03 & 5.6904 & 0.06 \\
\hline June & 8.3479 & 0.01 & 0.9723 & 0.01 & 0.0868 & 0.03 & 4.7716 & 0.09 \\
\hline July & 2.9800 & 0.22 & 0.9849 & 0.18 & 0.0502 & 0.61 & 2.8986 & 0.23 \\
\hline August & 7.6897 & 0.02 & 0.9724 & 0.01 & 0.0766 & 0.07 & 5.3172 & 0.07 \\
\hline September & 6.8940 & 0.03 & 0.9768 & 0.04 & 0.0638 & 0.26 & 10.689 & 0.00 \\
\hline October & 3.3396 & 0.18 & 0.9813 & 0.08 & 0.0475 & 0.70 & 2.9346 & 0.23 \\
\hline November & 0.9648 & 0.62 & 0.9895 & 0.49 & 0.0573 & 0.42 & 1.3732 & 0.50 \\
\hline December & 10.534 & 0.00 & 0.9669 & 0.00 & 0.0773 & 0.07 & 6.1603 & 0.04 \\
\hline
\end{tabular}

If the assumption of the normality of the temperature factor distributions is considered (table 5), then in the cross-section of individual months for monthly 
data only in three cases it can be said that there is no approximation to normality. In most variants, the hypothesis that the distributions are normal is confirmed. However, a similar analysis across months, but for daily data, gives quite different results. The hypothesis being verified, in this case, is much less common.

Referring to the issue of variance (table 4), the issue of changing values of this distribution parameter should be mentioned. By testing this with the BreuschPagan test (Breusch i Pagan, 1979), the hypothesis about the constancy of unconditional variance should be rejected. Thanks to testing the ARCH effect (Engle, 1982) one can conclude that there is a variable conditional variance.

\section{The nature of the weather indices variability}

Weather affects economic operators in different ways. In order to hedge these different types of threats, weather derivatives are based on a variety of weather variables and may depend on more than one such variable (table 1).

The investment potential of weather derivatives is described in the publication by J. Preś (Preś, 2007). In the research conducted he proves that in order to protect against the risk of adverse weather conditions, derivatives based on temperature indices are most often used. As J. Preś claims that their main advantage is independence from financial markets. This state of affairs also results from the fact that the investment technique that can be used in the case of weather futures contracts is the portfolio analysis (technical analysis is not relevant in this case as weather indices, which are the basic assets of derivatives, are shaped by nature, and not by supply and demand). Due to the development of globalization and technological progress, the capital market on a global scale is more and more often perceived as a system of connected vessels. Meanwhile, portfolio analysis requires optimization of the portfolio by including components with the highest expected rate of return and, at the same time, the smallest correlation between them. These are the properties of the temperature indices mentioned above (Mentel, 2017).

When analyzing selected combinations of portfolios, J. Preś proves that including derivative instruments based on HDD/CDD indices into the portfolio results in better results than if two other financial values were added. At a given level of risk, the best profitability is always obtained from a portfolio that includes derivatives based on HDD/CDD indices. The profitability of the basic portfolio after the addition of two instruments based on HDD/CDD indices increases by an average of $20 \%$, while the addition of two other equity market values increases the average profitability of the entire portfolio by only $8 \%$.

The most frequently used weather factor is therefore temperature, given as an hourly value, daily minimum or maximum, or in the (most common) form of daily averages.

In most countries, the daily average is defined as the midpoint of the minimum and maximum daily temperature levels. However, in some countries this value is defined as a weighted average of more than two temperature values per day. It is then estimated at three, twelve, twenty-four or more daily values. The exact time at 
which the minimum and maximum temperatures are measured and the exact determination of minimum and maximum levels also vary from country to country. In order to participate in the weather market, you must carefully study the weather measurement conventions in each of them (Jewson i Brix, 2010).

The index values in question for a specific day are calculated according to the following formulas (Göncü, 2012):

$$
\begin{aligned}
H D D_{i} & =\max \left(18^{\circ} \mathrm{C}-T_{i}, 0\right) \\
C D D_{i} & =\max \left(T_{i}-18^{\circ} \mathrm{C}, 0\right)
\end{aligned}
$$

where $T i$ is the average daily temperature.

The values of the $H D D$ and $C D D$ indices for the entire billing period are calculated as the sum of their daily values covered by this period, i.e. (Zeng, Pricing weather derivatives, 2000):

$$
\begin{aligned}
& H D D_{n}=\sum_{i=1}^{n} H D D_{i} \\
& C D D_{n}=\sum_{i=1}^{n} C D D_{i}
\end{aligned}
$$

where $n$ is the number of days in the period.

Thus, it follows that these indices are non-decreasing in their entire field. Moreover, the indices constructed in this way in the winter (HDD) and summer $(C D D)$ months have the features of Asian indices and are linear ${ }^{5}$. In months when the average daily temperature may be higher than $18^{\circ} \mathrm{C}$, the $H D D^{6}$ index becomes non-linear and cannot be calculated on the basis of the average temperature in a given period (the opposite is true for the $C D D$ index).

Regardless of the type of temperature indices underlying the settlement of forward weather contracts, it is stated that they are seasonal in terms of both the average index and volatility. This information is important for the valuation of any instrument based on this type of index. While the so-called seasonality in the average is not of great importance, as the strike prices of derivative instruments take into account seasonal temperature changes, the seasonality of volatility of these indices already exists. Its size affects the valuation. Seasonal volatility of indices allows establishing possible regularities specific to a given market.

The aforementioned seasonality in the average is illustrated in Figure 5. In addition to the expected value (illustrated on the example of the $H D D$ index), the graphical presentation also shows the absolute volatility of this index. It is noticeable that the absolute volatility is high in the winter months, as is the average

\footnotetext{
5 'Linearity' means that the daily index values are a linear function of the daily values of a weather variable, for example the average air temperature. Asian instruments are settled on the average value of the basic asset over a given period.

${ }^{6}$ The $H D D$ and $C D D$ indices are the main indices used in stock exchange trading. However, in European conditions, the CAD index (Cumulative Average Temperature) and Frost Days are also used; in the Japanese market index MAT (Monthly Average Temperature).
} 
Weather Derivatives Instruments. Property Analysis of the Basic Instruments

value of the index itself, while the opposite tendency is noticeable in the summer months. The fall in the index value is also accompanied by a fall in its volatility.
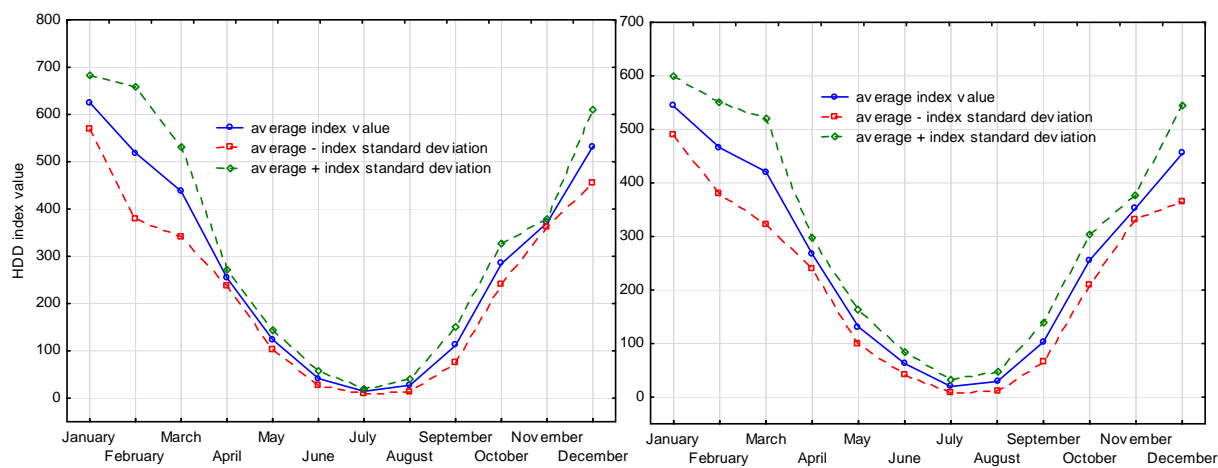

Figure 5. The expected values of the HDD index along with their deviations in individual months of the year in Rzeszów and Szczecin in 2012-2017

Source: The authors' own research

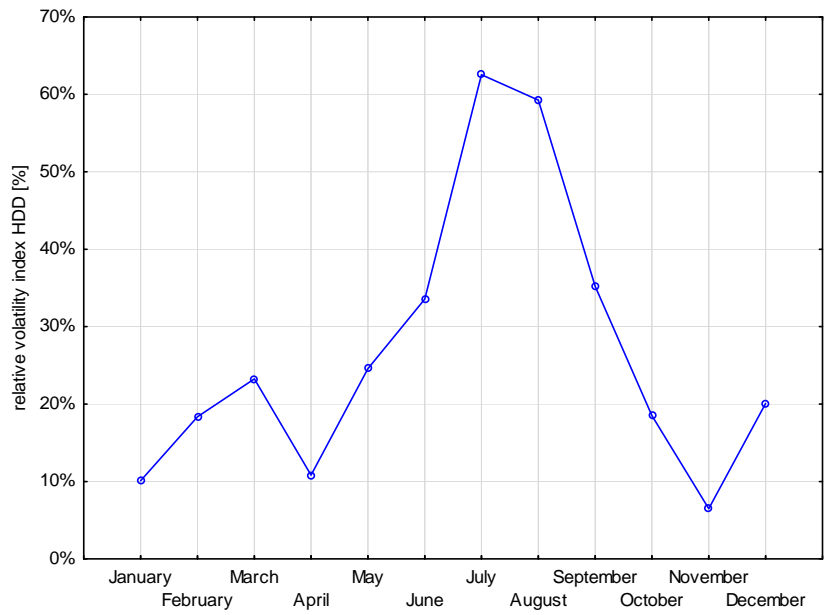

Figure 6. The expected values of the HDD index along with their deviations in individual months of the year in Szczecin in 2012-2017

Source: The authors' own research

The absolute variability of the indices is smaller than a decrease in the average value of these indices alone, as a result of which the relative variability is higher in the warmer months (Figure 6). The regularity is clearly visible that with a growth of the index value, the absolute volatility increases and the relative volatility decreases. In the case of a decrease in the value of $H D D$, these relations are opposite, then a decrease in the absolute variability and an increase in the relative 
variability are observed. Importantly, the observed trend is analogous to other temperature indices underlying financial settlements of derivatives ${ }^{7}$. The cyclicality of its repetition is important both for those who evaluate this type of instruments and for investors.

In order to investigate the possible impact of the indicated regularities on the market of weather derivatives, the formulas determining both the value of the payment and the purchase/sales price should be analyzed. This is important as the profitability measures are relative measures, which also allows the assumption that instruments based on temperature indices are more risky in particular periods of the year due to increasing relative volatility. As indicated earlier, this regularity translates significantly into the valuation of an instrument based on this type of indices.

The formula describing the price of a financial derivative instrument determines the expected value of payment taking into account the risk (Henderson, 2002) is as follows:

$$
C=E(P)+R(P)
$$

where:

$E(P)$ - value of the expected payment,

$R(P)$ - factor reflecting the uncertainty of the payment, treated as a random variable with parameters of an average of zero and the variance taking into account the total contract risk.

of:

Thus, the purchase and sale price of such an instrument may take the form

$$
C_{\frac{\text { purchase }}{\text { sales }}}(t)=D(t, T)\left[E(P) \pm F_{\frac{\text { purchase }}{\text { sales }}}(R(P))\right]
$$

where:

$D(t, T)$-factor discounting the value of the instrument from $T$ to the valuation period $t$,

$F_{\frac{\text { purhase }}{\text { sales }}}-$ function representing the propensity of the value to risk.

By changing slightly the form of equation (6) and taking into account the dependence of the payout from the derivative on the basic index, the instrument's price formula takes the form:

$$
C_{\frac{\text { purchase }}{\text { sales }}}(t)=D(t, T)(\mu \pm \alpha \cdot \sigma)
$$

where:

$\mu$ - expected index value,

\footnotetext{
${ }^{7}$ The study took into account temperature data for 16 provincial cities in Poland. The $H D D, C D D$ and $C A D$ indexes were taken into account.
} 
$\alpha$ - individual risk-aversion ratio,

$\sigma$ - relative volatility of the instrument ${ }^{8}$.

To sum up, the indicated trends with respect to the volatility of indices based on temperature values are reflected in the values of weather derivatives. The observed regularities allow greater predictability of investments in these instruments. Hence, the weather futures market is often referred to as "well behaved" (Zeng i Perry, 2002).

In order to confirm the correctness of the observations ${ }^{9}$ described, they should be verified in terms of the actual prices of instruments. This is currently problematic as we deal with the issue of a short history of the weather derivatives market, limited access, and relatively low liquidity in the weather options market. Consideration should also be given to taking these regularities into account when determining the amount of guarantee deposits.

\section{Conclusion}

In view of the many threats resulting from changing weather conditions, it makes sense to constantly counteract this type of risk. Since its scope covers a significant part of the economy, any research aimed at optimizing weather risk management should be developed as much as possible.

However, referring to the observations made so far, it should be emphasized that the physical control of this type of risk is extremely difficult, and its avoidance is practically impossible. Therefore, all tools, even the most effective ones, are used to financially manage (non-catastrophic) weather risk. Transferring threats outside the enterprise on the basis of a contract seems to be the most correct form Today, effective mitigation of the dangers of weather factors is limited to weather derivatives. This mainly results from the fact that it is not possible to use natural hedging for the threats under consideration. In this case, this type of risk cannot be related to the production volume or fixed assets. Therefore, this state of affairs is determined by the fact that specially constructed financial instruments are an effective instrument of weather risk management.

Their application is of great importance. Firstly, they allow a much greater focus on the company's core business, and moreover, by excluding the risk of weather, resources are freed up for its core business. Thanks to this, their use

\footnotetext{
${ }^{8}$ In the case of temperature indices used in the market, their distributions are close to normal. Then, the relative volatility of the index can be measured by standard deviation. Distributions of indexes created taking into account other weather characteristics require the use of different measures.

${ }^{9}$ Possible verification of the correctness that the temperature indices underlying the settlement of financial derivative instruments, apart from the obvious seasonality in the average, also show regularity in the volatility of these indices $t$ is difficult to perform in Poland due to difficulties in obtaining data. Even the possible receipt of them results in the presented weather time series for daily data being too short. Therefore, all analyzes of this type were conducted for data from the American market. An example of such research can be found in the works of J. Preś (Preś, 2007).
} 
removes problems resulting from its essence from the subject and allows paying attention to the current activity. Secondly, weather derivatives allow cash flow to be significantly stabilized. They allow the reduction of the weather risk by entering into a forward transaction that is opposite to the basic position already held. Third, their use significantly improves fluidity.

This is achieved by eliminating fluctuations in cash flows, thus improving the financial liquidity of the entity. However, it should be remembered that these are only the most important facts in favor of their use.

The development of the market of derivative weather instruments depends, however, on the reliability of weather data and the ease of obtaining them.

\section{REFERENCES}

[1] Banks, E. (2002), Weather Risk Management. Market, Products and Applications. Palgrave Macmillan, UK;

[2] Bilan, Y., Mentel, G., Streimikiene, D., Szetela, B. (2020), Weather Risk Management in the Weather-VaR Approach. Assumptions of Value-at-Risk Modeling. Economic Computation and Economic Cybernetics Studies and Research, 1/2020; ASE Publishing, Bucharest;

[3] Breusch, T., Pagan, A. (1979), A Simple Test of Heteroskedasticity and Random Coefficient Variation. Econometrica, no. 47, 1287-1294;

[4] Campbell, S. i Diebold, F. (2005, March), Weather Forecasting for Weather Derivatives. Journal of the American Statistical Association, no. 100(469);

[5] Corbally, M. i Dang, P. (2002), Underlying Markets and Indexes. W E. Banks, Weather Risk Management: Markets, Products and Applications. New York: Palgrave, 87-104;

[6] Endress, T. (2018), Deliberated Intuition in Stock Price Forecasting. Economics and Sociology, 11(3), 11-27. doi:10.14254/2071-789X.2018/11-3/1

[7] Engle, R. (1982), Autoregressive conditional heteroskedasticity with estimates of the variance of $U K$ inflation. Econometrica, no. 50;

[8] Forrest, P. (2002), A Case Study of Heating Oil Partners. Weather Hedging Experience, [in:] Dischel, B. (ed.), Climate Risk and the Weather Market, Risk Books;

[9] Göncü, A. (2012), Pricing Temperature-based Weather Derivatives in China. The Journal of Risk Finance, no. 13(1), 2-44;

[10] Henderson, R. (2002), Pricing Weather Risk, [in:] E. Banks (ed.), Weather Risk Management. Palgrave;

[11] Hull, J. (2009), Options, futures and other derivatives. New Jersy: Pearson Education Inc.

[12] Jewson, S. (2001), Weather Risk and Weather Data. Environmental Finance, no. $2-3$;

[13] Jewson, S. (2002), The Use of Weather Forecast in the Pricing of Weather Derivatives. Meteorological Applications, no. 3;

[14] Jewson, S., Brix, A. (2010), Weather Derivative Valuation. The Meteorological, Statistical, Financial and Mathematical Foundations. Cambridge University Press, Cambridge; 
Weather Derivatives Instruments. Property Analysis of the Basic Instruments

[15] Kupczyk, J. (2003), Analiza ekonometryczna indeksów pogodowych instrumentów pochodnych. Prace Naukowe Akademii Ekonomicznej we Wrocławiu, 1006;

[16] L'opez Cabrera, B. i Hardle, W. (2007), Weather Derivatives. Berlin: CASECenter for Applied Statistics and Economics, Humboldt-Universitat zu Berlin;

[17] Majewska, A. (2013), Instrumenty pochodne jako narzędzia wspomagające zarzadzanie ryzykiem w przedsiębiorstwie. Szczecin: Volumina.pl;

[18] Melonek, M. (2011), Porównanie wyników weryfikacji modeli numerycznych prognoz pogody dzialajacych operacyjnie w ICM, Infrastruktura i Ekologia Terenów Wiejskich, no. 6, 31-42;

[19] Mentel, G., (2017), Wartość zagrożona jako instrument zarządzania ryzykiem pogodowym. Oficyna Wydawnicza Politechniki Rzeszowskiej;

[20] National Oceanic \& Atmospheric Administration, U.S. Department of Commerce (2016). Earth System Research Laboratory - Physical Science Division, http://www.cdc.noaa.gov/map/images/ens/ens.html;

[21] Oliinyk, V. \& Kozmenko, S. (2019), Forecasting and Management of Gross Domestic Product. Journal of International Studies, 12(4), 214-228. doi:10.14254/2071-8330.2019/12-4/14;

[22] Preś, J. (2007), Zarządzanie ryzykiem pogodowym. CeDeWu, Warszawa;

[23] Schulzweida, U. i Quast, R. (2005). Climate indices with CDO. Climate indices of daily temperature and precipitation extremes. $\mathrm{CDO}$;

[24] Shorter, J., Crawford, T., Boucher, R. (2002), Skillful Seasonal Degree Day Forecasts and Their Utility in the Weather Derivatives Market. 16th Conference on Probability and Statistics in the Atmospheric Science;

[25] Tarczyński, W., Majewski, S., Tarczyńska-Luniewska, M., Majewska, A., Mentel, G. (2021), The Impact of Weather Factors on Quotations of Energy SectorCompanies on Warsaw Stock Exchange. Energies, 14(1536). doi:10.3390/en14061536;

[26] Unisys Weather Information Systems (2016); http://weather.unisys.com/ecmwf ;

[27] Zeng, L., Perry, K.D. (2002), Managing a Portfolio of Weather Derivatives, [in:] Dischel, B. (ed.), Climate Risk and the Weather Market. Risk Books;

[28] Ziehman, C., Brix, A., Jewson, S. (2002), Use of Meteorological Forecast in Weather Derivative Pricing, [in:] Dischel, B. (ed.), Climate Risk and the Weather Market. Risk Books. 